\title{
Risk-Factor Analysis for Feline Hyperthyroidism in the Metropolitan Area of Porto Alegre: A Pilot Case-Control Study
}

\author{
Claudia Ruga Barbieri' ${ }^{1 *}$ and Alan Gomes Poppl ${ }^{2}$ \\ ${ }^{1}$ Faculdade de Veterinária (FaVet), UFRGS. Av. Bento Gonçalves 9090, Bairro Agronomia, Brazil \\ ${ }^{2}$ Departamento de Medicina Animal (DMA), Universidade Federal do Rio Grande do Sul (UFRGS), Brazil
}

Submission: April 15, 2019; Published: August 29, 2019

*Corresponding author: C R Barbieri, Faculdade de Veterinária - UFRGS. Av. Bento Gonçalves 9090, Bairro Agronomia. CEP $91540-000$ Porto Alegre, RS, Brazil

\begin{abstract}
Background: Hyperthyroidism is the most common endocrinopathy in elderly cats and its prevalence varies greatly geographically. Since it was first described in 1979, it has shown a continuously increasing incidence. This fact has given rise to several hypothesis, and studies about the effects of endocrine disruptors on human and animal health are in full development. Aging, bisphenol-A and other endocrine disruptors present in the dust, were already documented as risk factors for feline hyperthyroidism. The aim of this study was to perform a risk analysis on the habits and lifestyle variables of domestic cats and their owners, and its possible relationship with feline hyperthyroidism.
\end{abstract}

Materials, Methods and Results: Retrospective case-control epidemiological study. A 30-questions questionnaire was applied to owners of 28 hyperthyroid cats as well as to owners of 55 euthyroid cats aging more than eight-years (n:m) and living in the metropolitan area of Porto Alegre - RS. Criteria for hyperthyroidism diagnosis was assumed as compatible clinical presentation confirmed by elevated serum thyroxine concentration. Euthyroid control cats were selected by convenience from hospital medical records based on the absence of hyperthyroidism diagnosis and age. Univariate odds ratio (OR) and respective $95 \%$ confidence interval $(95 \% \mathrm{CI}$ ) analysis was performed for each of the 22 variables surveyed. Exact Fischer's test was performed to determine P-value, which was considered significant if $\mathrm{P}<0.05$. Student's unpaired t-test was applied for age comparison between groups. Mean age of hyperthyroid cats was $13.2 \pm 2.7$ years (range: 7-18), while euthyroid cats mean age was $11.6 \pm 2.4$ years (range: $8-16)(\mathrm{P}<0.01)$. Higher exposure to canned foods was considered as a risk factor for hyperthyroidism in this population $(\mathrm{OR}=2.87 ; 95 \% \mathrm{CI}=1.1-7.5 ; \mathrm{P}=0.032)$ as well as aging more than 12 -years-old $(\mathrm{OR}=3.14 ; 95 \% \mathrm{CI}=1.10-8.97 ; \mathrm{P}=0.048)$. Likewise, weekly or monthly bathing frequency represented a strong risk factor in those hyperthyroid cats studied $(\mathrm{OR}=7.57 ; 95 \% \mathrm{CI}=1.41-40.55 ; \mathrm{P}=0.013)$. Regarding other items surveyed, such as the use of plastic accessories, contact with domestic dust, use of endoparasiticides, ectoparasiticides and vaccines, it was not possible to identify any association of these variables as risk or protective factors.

Discussion: Even with a modest sample size, these results were in accordance with previous studies that analyzed hundreds of cats showing that advanced age, as well as the consumption of canned foods, are risk factors for the development of the disease. This study also raised the possibility of a risk factor related to frequent bathing. The explanation would be due to the possible presence of endocrine disruptors in cosmetic products used for bathing. This hypothesis needs further studies, since previous recommendations on hyperthyroidism preventive management suggests that bathing could have a protective effect since it cleans off the dust particles present in the fur. However, evidences that triclosan and parabens present in cosmetic products may act as thyroid endocrine disruptors have been recently raised. Further studies would be required to determine the effects of such inputs in felines' health, since the etiopathogenesis of hyperthyroidism is uncertain and surely multifactorial. These genetic, environmental, and nutritional factors; should be analyzed together, as far as possible. Moreover, these findings are helpful to create preventive strategies against feline hyperthyroidism and corroborate with data previous published in epidemiological studies in other countries.

Keywords: Cats; Canned food; Aging; Thyroid hormones; Endocrine disruptors

\section{Introduction}

Feline Hyperthyroidism (FH) is a multisystemic disorder resultingfromexcesscirculatingconcentration oftriiodothyronine (T3) and thyroxine (T4) produced by an abnormally functioning thyroid gland which affect mainly elderly cats [1]. The most frequent signs are polyphagia, polyuria, polydipsia, weight loss, hyperactivity, vomiting, diarrhea and an unkempt hair coat among other manifestations. The FH is considered a worthy cause of comorbidities and eventual death due to the deleterious effects of secondary chronic hypermetabolism [2]. Since it was first described in 1979, its incidence is continuously increasing. 
The higher risk of developing the disease is being related to indoor life and consumption of canned food, due to the exposure to agents acting as endocrine disruptors (ED).

These compounds are exogenous agents that interferes with the synthesis, secretion, transport, metabolism, binding action or elimination of natural-borne hormones through various mechanisms [3]. By those ways, ED might block or mimic hormone action causing various effects [4]. These substances are present in plastics, metal food cans, flame retardants, food additives, cosmetics, and pesticides. The ED are represented most frequently by the polychlorinated biphenyls (PCBs), bisphenol-A (BPA), phthalates [4] and the polybrominated diphenyl ethers (PBDEs) present in the house dust and considered global contaminants $[5,6]$. The objective of this study was to analyze how habits and lifestyle of domestic felines and their owners might represent risk or protection factor for the FH development in a population of cats in the metropolitan area of Porto Alegre, Rio Grande do Sul, Brazil.

\section{Materials and Methods}

\section{Study Design}

Epidemiological retrospective case-control study to analyze the risk of exposure to diverse factors related do feline hyperthyroidism.

\section{Animals}

A convenience sampling of feline patients diagnosed with hyperthyroidism was performed. The patients' data were obtained from the medical records of a veterinary teaching hospital and two private clinics, one of which exclusively dedicated to feline care and treatment, all located in the city of Porto Alegre, Rio Grande do Sul, Brazil. As criteria for the diagnosis of hyperthyroidism, the presence of clinical signs and compatible laboratory abnormalities, palpable thyroid and/ or serum total T4 concentration were determined. The control group were selected from the same establishments than cases, since there was no history of hyperthyroidism, were above 8 years of age, and living in the metropolitan region of Porto Alegre.

\section{Questionnaire}

A thirty objective multiple-choice questions questionnaire about risk factors for feline hyperthyroidism development previously studied in other world regions, including several possible endocrine disruptors was elaborated. Most questions were adapted from questionnaires previously used in epidemiological studies that evaluated risk factors for the disease [1,5-8] and included a total of 22 variables under study. Hyperthyroid cats' owners answered four more questions at the end of the questionnaire, regarding the therapeutic options employed and case outcome. Hyperthyroid cats' owners were asked to answer the questions based on the patient's lifestyle prior to the diagnosis of hyperthyroidism. The control patients group owners were asked to answer questions based on the current lifestyle of patients to avoid recall bias. The time interval for completing the questionnaire ranged from five to 15 minutes accordingly to owner's eloquence.

The same interviewer applied all questionnaires after training techniques for epidemiological questionnaires appliance. Prior to its application, a telephone contact was made to present the research to the owner and obtain consent to participate. During the telephone call, the owners were asked about the best time to take part in the survey. If they want, they could answer the questionnaire at the same time or schedule a proper time to answer the questionnaire. Some owners requested to send the questionnaire electronically so that they could answer it at a more appropriate time. This request was accepted to avoid any information bias. Also, some questionnaires answered were obtained in person from owners by the time they brought their cats to the veterinary establishments. Despite the multiplechoice design of the questionnaire, all answers were converted to dummy (dichotomous) variables showing exposure or nonexposure to the analyzed factor [9].

\section{Variables under study}

The "Sex" variable was classified as male or female, considering being female as a risk factor. "Age" variable was classified into two categories (seven to 12 years of age or above 12 years of age). Ages equal or over 12 years were considered a risk factor. The "Pouch cat food" and "Canned cat food" variables were classified as a risk factor if the frequency of feeding was daily, weekly or monthly. "Food bowls" and "Water bowls" variables were considered a risk factor if made of plastic in contrast with porcelain, glass, aluminum, or stainless-steel bowls. The "Use of plastic bowls for both water and food" was classified as a risk factor when compared to the sole use of the other listed materials. The "Use of cat litter box" variable was classified as a risk factor when compared to cats that did not use it.

The use of "Cat litter" variable was classified as sand, silica, newspaper or wood pellets, where silica and sand (mineral basis) were considered risk factors. The "Kind of Home" variable was considered a risk factor if the cat lived in an urban apartment when compared to urban, beach or farmhouses. The "Environment" variable was classified as risk factor when the cats were exclusively indoor. The "Amount of time spent outdoor" variable was classified as a risk factor when the cat was exclusively indoor or indoor cats who spent up to one hour a day outside. The "Use of carpets" variable was classified as a risk factor if there was presence of carpets in the house. The "Frequency of home cleansing" was classified as a risk factor if it was done monthly or less frequent. The "bathing frequency" variable was classified as a risk factor when bathing daily, weekly or monthly.

The "Vaccine" variable was classified as a risk factor when done on an annual basis or every 2 to 3 years when compared to vaccination done only when kitten or eventually. The "Deworming" variable was classified as risk factor if done 
monthly basis or according to manufacturer's instructions when compared to eventual deworming. The "Use of ectoparasiticides" variable was classified as a risk factor when used in a monthly basis or according to manufacturer's instructions when compared to eventual use. The "Contact with plastic toys" variable was classified as risk factor when the cat played with plastic toys.

\section{Statistical Analysis}

Univariate odds ratio (OR) and respective 95\% confidence interval $(95 \% \mathrm{CI})$ analysis was performed for each of the 22 variables surveyed. Exact Fischer's test was performed to determine P-value, which was considered significative if $\mathrm{P}<$ 0.05. Student's unpaired t-test was applied for age comparison between groups. To perform statistical analysis the package Prism GraphPad version 6.0 was used.

\section{Results}

From a total of 94 questionnaires applied, 83 were eligible to be included in the study, of which 28 referred to hyperthyroid cats (cases) and 55 referred to euthyroid cats (controls) over 8 years of age (n:m). Among the cases, one questionnaire was excluded since the diagnosis of hyperthyroidism had not been confirmed by total T4 result. Two owners preferred not to answer the questionnaire due to the animals' death. In eight other contacts, it was not possible to identify the motivation for not answering the questionnaire. Concerning cases demographic distribution, there were $48 \%$ male patients and $52 \%$ female patients, a distribution like that observed among controls ( $47 \%$ males and $53 \%$ females) and there was no evidence of gender being a risk factor in this population. The mean age of the animals by the time of FH diagnosis was $13.2 \pm 2.7$ years, ranging from seven to 18 years of age, whereas in the control group (euthyroid), the mean age at the time of application of the questionnaire was $11.6 \pm 2.4$ years, ranging from eight to 16 years of age (Figure 1). Despite the careful selection of controls with more than eight years of age for the study and the unusual occurrence of a seven-year-old case, the control group was statistically younger than the case group in the comparison done by the non-parametric t-Student test $(\mathrm{P}<0.01)$.

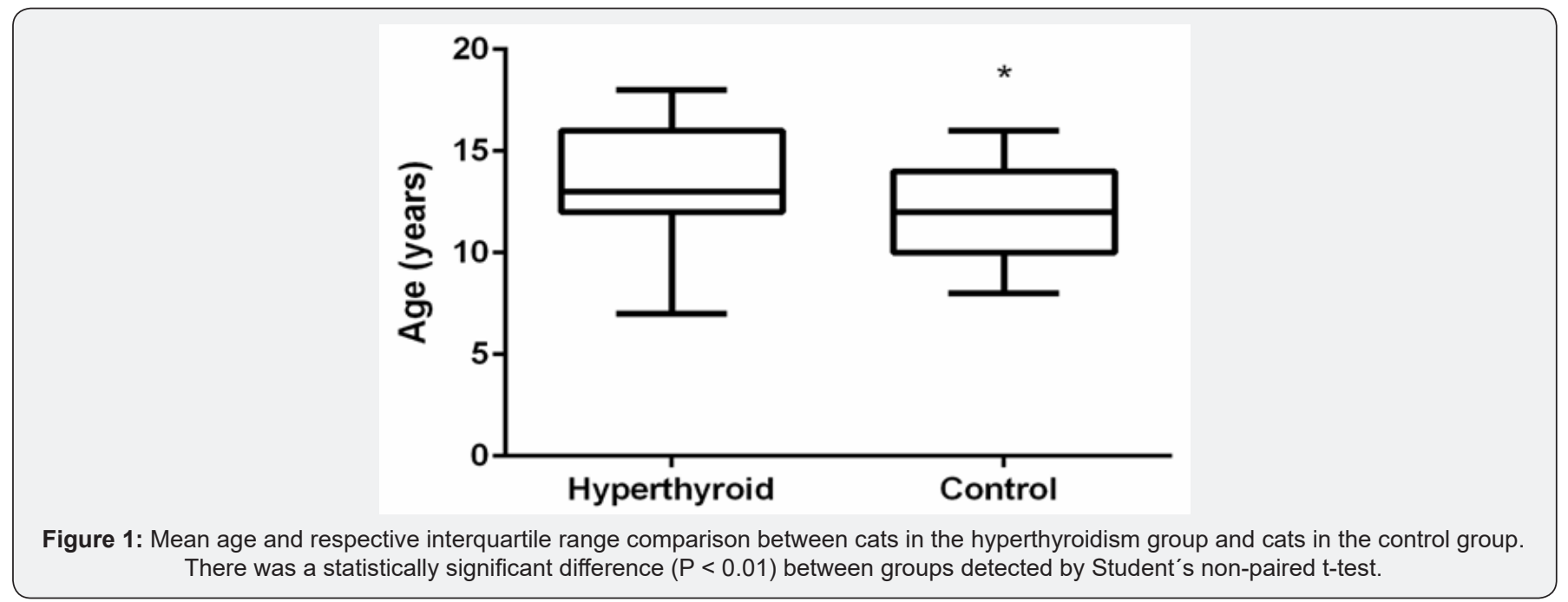

To evaluate the age as a risk factor, cases were categorized into two subgroups for comparison purposes: "geriatric" subgroup (age seven to 11 years, 11 months and 30 days), and "senile" subgroup > 12 years). The senile category represented a significant risk factor $(\mathrm{OR}=3.14 ; 95 \% \mathrm{CI} 1.10$ to $8.97 ; \mathrm{P}=$ 0.032). The exposure to canned food consumption (commercial moist food, tuna or sardines) represented a significant risk factor $(\mathrm{OR}=2.87 ; 95 \% \mathrm{CI} 1.1$ to $7.5 ; \mathrm{P}=0.048)$ when comparing to rare or non-consumption of these kind of food. Likewise, the exposure to bathing also represented a risk factor associated with hyperthyroidism in the studied population $(\mathrm{OR}=7.57 ; 95 \%$ CI 1.41 to $40.55 ; \mathrm{P}=0.013$ ). The complete data from statistically significant data are presented in Table 1. Concerning the other analyzed variables (plastic bowls, plastic toys, cat litter boxes and cat litter, environmental characteristics, use of endoparasiticides, ectoparasiticides and vaccines), no statistically significant differences in exposure between cases and controls were found, as shown in Table 2.

Table 1: Odds ratio and $95 \%$ confidence intervals of the statistically significant analyzed variables.

\begin{tabular}{|c|c|c|c|c|}
\hline \multirow{2}{*}{ Analyzed Variables } & Hyperthroid $(n=27)$ & Control $(n=55)$ & \multirow{2}{*}{ OR (CI 95\%) } & \multirow{2}{*}{ P-value } \\
\hline & n (\%) & n (\%) & & \\
\hline \multicolumn{5}{|l|}{ Age } \\
\hline > 12 years & $21(78)$ & $29(53)$ & $3.14(1.10-8.97)$ & 0.032 \\
\hline $7-12$ years & $6(22)$ & $26(47)$ & & \\
\hline Canned Cat Food & & & & \\
\hline
\end{tabular}




\section{Journal of Endocrinology and Thyroid Research}

\begin{tabular}{|c|c|c|c|c|}
\hline Daily/Weekly/Monthly & $14(52)$ & $15(27)$ & $2.87(1.10-7.50)$ & 0.048 \\
\hline Rarely/Never & $13(48)$ & $40(73)$ & & \\
\hline \multicolumn{5}{|l|}{ Bathing Frequency } \\
\hline Daily/Weekly/Monthly & $6(22)$ & $2(4)$ & $7.57(1.41-40.55)$ & 0.013 \\
\hline Rarely/Never & $21(78)$ & $53(96)$ & & \\
\hline
\end{tabular}

OR: Odds-Ratio; *: Cl 95\% significant $(\mathrm{P}<0,05)$

Table 2: Odds ratio and $95 \%$ confidence intervals of the statistically significant analyzed variables.

\begin{tabular}{|c|c|c|c|c|}
\hline \multirow{2}{*}{ Analyzed Variables } & Hyperthroid $(n=27)$ & Control $(n=55)$ & \multirow{2}{*}{ OR (CI 95\%) } & \multirow{2}{*}{ P-value } \\
\hline & n (\%) & n (\%) & & \\
\hline \multicolumn{5}{|l|}{ Sex } \\
\hline Male & $13(48)$ & $26(47)$ & $0.97(0.38-2.43)$ & 1 \\
\hline Female & $14(52)$ & $29(53)$ & & \\
\hline \multicolumn{5}{|l|}{ Pouch Cat Food } \\
\hline Rarely/Never & $7(26)$ & $22(40)$ & $1.90(0.69-5.26)$ & 0.231 \\
\hline Daily/Weekly/Monthly & $20(74)$ & $33(60)$ & & \\
\hline \multicolumn{5}{|l|}{ Water Bowls } \\
\hline Plastic & $19(70)$ & $30(55)$ & $1.98(0.74-5.28)$ & 0.232 \\
\hline Porcelain, stainless-steel, glass & $8(30)$ & $25(45)$ & & \\
\hline \multicolumn{5}{|l|}{ Food Bowls } \\
\hline Plastic & $18(67)$ & $32(58)$ & $1.44(0.55-3.77)$ & 0.483 \\
\hline Porcelain, stainless-steel, glass & $9(33)$ & $23(42)$ & & \\
\hline \multicolumn{5}{|l|}{ Both Bowls material } \\
\hline Plastic & $15(56)$ & $22(40)$ & $1.88(0.74-4.76)$ & 0.239 \\
\hline Porcelain, stainless-steel, glass & $12(44)$ & $33(60)$ & & \\
\hline \multicolumn{5}{|l|}{ Use of Cat litter box } \\
\hline Yes & $26(96)$ & $46(84)$ & $5.09(0.61-42.43)$ & 0.154 \\
\hline No & $1(4)$ & $9(16)$ & & \\
\hline \multicolumn{5}{|l|}{ Kind of Cat litter } \\
\hline Sand/Silica & $22(81)$ & $38(69)$ & $1.16(0.31-4.29)$ & 1 \\
\hline Wooden pellets/newspaper & $4(15)$ & $8(15)$ & & \\
\hline \multicolumn{5}{|l|}{ Kind of home } \\
\hline Apartament (urban) & $19(70)$ & $36(65)$ & $1.25(0.46-3.39)$ & 0.803 \\
\hline House (urban, farm, beach) & $8(30)$ & $19(35)$ & & \\
\hline \multicolumn{5}{|l|}{ Environment } \\
\hline Always indoor & $21(78)$ & $40(73)$ & $1.31(0.44-3.88)$ & 0.789 \\
\hline Part-time indoor/part-time outdoor & $6(22)$ & $15(27)$ & & \\
\hline \multicolumn{5}{|l|}{ Amount of time spent outdoor } \\
\hline More than up to one hour & $1(4)$ & $10(18)$ & $0.17(0.02-1.43)$ & 0.091 \\
\hline Up to one hour & $26(96)$ & $45(82)$ & & \\
\hline \multicolumn{5}{|l|}{ Use of carpets } \\
\hline Yes & $13(48)$ & $23(42)$ & $1.29(0.51-3.26)$ & 0.641 \\
\hline No & $14(52)$ & $32(58)$ & & \\
\hline \multicolumn{5}{|l|}{ Frequency of home cleansing } \\
\hline Daily/Weekly & $22(81)$ & $40(73)$ & $1.65(0.52-5.15)$ & 0.428 \\
\hline
\end{tabular}




\section{Journal of Endocrinology and Thyroid Research}

\begin{tabular}{|c|c|c|c|c|}
\hline Monthly/Rarely & $5(19)$ & $15(27)$ & & \\
\hline \multicolumn{5}{|l|}{ Vaccination $* *$} \\
\hline Yes & $22(81)$ & $46(84)$ & $0.77(0.22-2.61)$ & 0.751 \\
\hline No & $5(19)$ & $8(15)$ & & \\
\hline \multicolumn{5}{|l|}{ Frequency of vaccination } \\
\hline Annually/each 2 or 3 years & $18(82)$ & $32(70)$ & $1.97(0.56-6.88)$ & 0.383 \\
\hline Eventually/only when kitten & $4(18)$ & $14(30)$ & & \\
\hline \multicolumn{5}{|l|}{ Deworming $* *$} \\
\hline Yes & $26(96)$ & $52(96)$ & $1.00(0.09-11.55)$ & 1 \\
\hline No & $1(4)$ & $2(4)$ & & \\
\hline \multicolumn{5}{|l|}{ Frequency of deworming } \\
\hline Each 3-4 meses/semiannually & $15(58)$ & $27(52)$ & $1.26(0.49-3.26)$ & 0.809 \\
\hline Annually/eventually & $11(42)$ & $25(48)$ & & \\
\hline \multicolumn{5}{|l|}{ Ectoparasiticides } \\
\hline Yes & $18(67)$ & $42(76)$ & $0,62(0,23-1,71)$ & 0.429 \\
\hline No & $9(33)$ & $13(24)$ & & \\
\hline \multicolumn{5}{|l|}{ Frequency of ectoparasiticides } \\
\hline Monthly/as manufacturer's & $6(25)$ & $14(33)$ & $1,00(0,31-3,23)$ & 0.583 \\
\hline Eventually & $18(75)$ & $28(67)$ & & \\
\hline \multicolumn{5}{|l|}{ Plastic Toys $* *$} \\
\hline Yes & $8(33)$ & $22(40)$ & $0,75(0,27-2,05)$ & 0.623 \\
\hline No & $16(67)$ & $33(60)$ & & \\
\hline
\end{tabular}

Regarding the four final questions of the questionnaire, which were applied only to the owners of hyperthyroid patients, it was documented that most of the patients (74.1\%) started treatment immediately after the diagnosis. From these patients, $37 \%$ of the cats were being treated between one and 12 months, $14.8 \%$ between 13 and 24 months and $22.2 \%$ of the cats were being treated for more than 24 months. Four patients (14.8\%) were not treated for hyperthyroidism despite the diagnosis, and other three patients (11.1\%) died soon after diagnosis or within one month of starting treatment. The oral methimazole therapy was the main choice of clinicians responsible for the cases in the study population, followed by transdermic topical methimazole, radioiodine therapy and low iodine diet. The frequency of distribution for each hyperthyroidism treatment modality in this case series is shown in Figure 2.

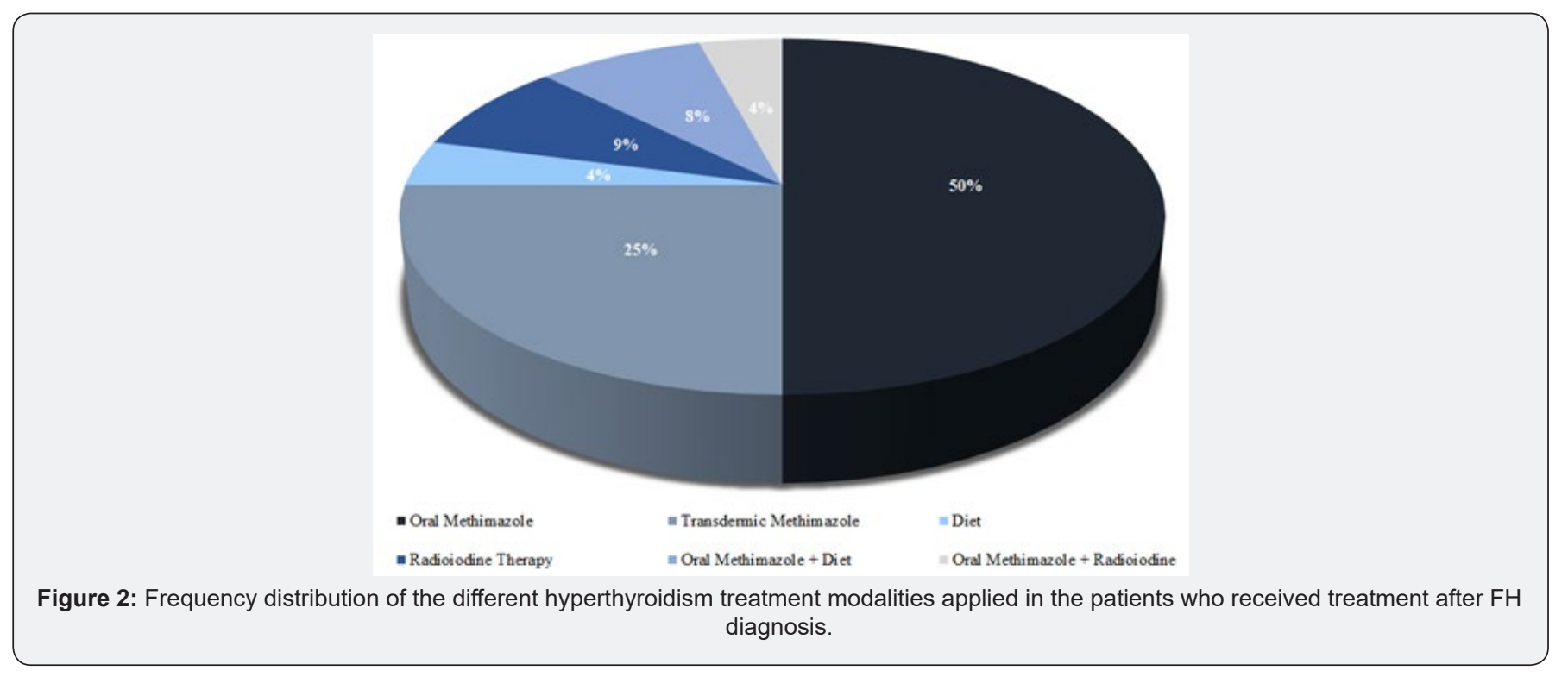




\section{Discussion}

The participation percentage of the owners in this research was considered high, since $88.3 \%$ of those who were contacted accepted to answer the questionnaire. However, a greater frequency of answers was observed in the hyperthyroid cat owners' group, which may be related to their greater knowledge about the disease, as well as their greater interest in helping to prevent future cases, and better understanding the problem. In contrast, the lowest percentage of answers from the euthyroid cat owners' group may have been motivated by the fact that they had not a closer relationship with this specific disease. Through the results achieved in the present study, it is possible to infer that advanced age can be considered an important risk factor for the development of $\mathrm{FH}$, which agrees with previous studies $[1,10,11]$. However, as the selection for control group considered patients over eight years of age, the evaluation of this variable depended on the establishment of a cutoff point for advanced age.

The relationship between advanced age and the development of hyperthyroidism might be explained, among other things, by the longer exposure to the substances that potentially act as endocrine disruptors, or by the simple fact that pathological thyroid changes related to hyperthyroidism are consequences of the aging process. As for the sex distribution, in contrast to the researches from New Zealand [4] and a London [12] which identified a higher predisposition for hyperthyroidism in females, the present study showed no significant difference in gender exposure in the studied population, in agreement with previous studies performed in the Ireland, the United Kingdom and Hong Kong $[1,10,13]$. However, the greater percentage of females in certain studies may represent a bias since eventually the females are more likely to reach an advanced age in relation to males due to the habits of the latter. In Brazil, there is a shortage of publications on feline hyperthyroidism, but the first FH cases series published in the late 2000s indicated a higher frequency in females $[14,15]$.

Until the present time, studies evaluating risk factors for feline hyperthyroidism development in Brazil were not found in the consulted database. Regarding the consumption of canned foods, the result obtained in this research agrees with previous studies $[16,17]$. This is an admittedly key factor, since the present study, even with a relatively small sample due to the low frequency of diagnosis of the disease in the region, obtained an OR like that described by an American study evaluating hundreds of patients [16]. Canned foods may have BPA in their inner lining, which migrates into the food during storage, or by contaminated components, and may constitute a risk factor for the development of endocrinopathies $[13,18]$. In addition, other studies have found evidence that this contamination is greater in pop-top cans $[7,18,19]$. It is worth mentioning that studies in rats have demonstrated that the main route of elimination of ingested BPA is through hepatic glucuronidation [20], which is greatly reduced in cats making this animal extremely sensitive to the adverse effects of many drugs and toxins that require glucuronidation before elimination [3]. Thus, slower clearance may lead to higher-than-expected BPA blood and tissue levels in cats [7].

Studies concerning the exposure of cats to PBDEs through canned foods and household dust suggest that the latter is the major source of exposure to this compound because of the hygienic habits of cats, as dust adheres to the fur when lying on the floor and ends being ingested by licking $[9,16]$. In this sense, one author suggests that cleaning the cats with a dry flannel and monthly bathing could provide an associated protective effect, since it removes the dust and consequently, the possible chemical agents present in the fur, leading to a reduction on the load of ED in the animal [18]. Despite this possibility, in the last decade there has been an increasing interest in finding out more information about the effects of some chemical substances of cosmetics, such as triclosan and parabens, on thyroid health. These two compounds are widely used in the cosmetics industry, but there is little research about their impact on endocrine health.

Triclosan is usually incorporated into several products, including soaps and shampoos, due to its antimicrobial effect. Parabens, in their turn, are used as preservatives for various products, including cosmetics. Just over a decade ago, the effects of these products on the thyroid were not investigated, but the interest in this subject is increasing and researchers are beginning to develop studies in this direction $[12,19]$. Recently, a study analyzed 60 urine samples from dogs and cats and demonstrated that parabens metabolites, notably benzoic acid and 4-hydroxybenzoic acid, were the most abundantly detected chemicals. Although the main purpose of this study was to identify the number of parabens originating from animal foods, it should be noted that these compounds are often used in cosmetics, which may also be a source of contamination. However, until the present moment, there is no available research about the effects specifically related to the development of feline hyperthyroidism.

Considering this trend, the purpose of the present study when analyzing the frequency of baths was to relate the use of shampoos and cosmetics in cats to the development of FH. From the results obtained, it was observed that hyperthyroid cats were 7.5 times more prone to have undergone frequent baths compared to the control group. However, a more detailed analysis is important to confirm this relationship, as the present study did not analyze the kinds of cosmetics nor the composition of the shampoos used to bathe the animals. One can speculate that hyperthyroid cats have been more exposed to bathing due to a greater care of their owners, once they are worried owners that went ahead investing in a FH diagnosis in the past. However, the use of hospital controls may have mitigated this probability once those owners were also looking for preventive or health care to their cats.

It should be considered that the present study had some limitations, such as the reduced number of animals in the 
sample, increasing the risk of type 2 statistical error. The fact that the several variables surveyed had $95 \%$ confidence intervals extremely wide, even though not significant, emphasizes the potential importance of these factors, so that the enlargement of the sample size could help to clarify this bias. The lower mean age of the control group, as well as the higher percentage of euthyroid cats between 8 and 12 years of age, may also have been a limiting factor, since most studies point to a mean age of diagnosis of feline hyperthyroidism among 12 and 13 years $[1,3,20-22]$.

Recall and confounding biases were also possible limitation of this study; however, this are recognized limitations of this kind of questionnaire-based research. General owner's inability to give accurate information about health status of their cats may have affected our results; however, we assume that this ability is similar for both case and control owners. Moreover, the use of hospital patients as controls, even though they were not hyperthyroid, may also work as a bias source. However, this approach helps us to select patients from the same population, a crucial case-control studies rule [23]. Misclassification bias is less likely in our study, even though controls were not diagnosed as hyperthyroidism at the time of the questionnaire, it is possible that some cats can be diagnosed with the disease and then being reclassified as cases in later years [24]. In addition, in the control group, cats with diseases other than feline hyperthyroidism were included, which may contribute to mask a possible hyperthyroidism due to T4 suppression and, consequently, associated clinical signs [25-27].

\section{Conclusion}

The results obtained in this research support previous studies conducted in other world regions that pointed to advanced age and consumption of canned foods as the main risk factors for FH. The positive relationship between bathing frequency and FH may be consistent due to exposure to compounds such as parabens, although there is a need for more comprehensive studies regarding the products used as well as their composition. The fact that the other variables analyzed did not represent a risk or protection factor in this population suggests that larger studies are necessary including other regions of the national territory, since the etiopathogenesis of feline hyperthyroidism is multifactorial and covers a series of genetic, nutritional and environmental factors, which should be analyzed together as far as possible. Nevertheless, the results achieved here opens the perspective of designing preventive strategies, such as avoiding the use of canned foods and reducing bathing frequency. However, to consider the reduction of exposure to these factors as a protective measure depends on the performance of prospective studies.

\section{References}

1. Bree L, Gallagher B A, Shiel R E, Mooney C T (2018) Prevalence and risk factors for hyperthyroidism in Irish cats from the greater Dublin area. Ir Vet J 71(2): 1-10.
2. Carney H C, Ward C R, Bailey S J, Bruyette D, Dennis S, et al. (2016) AAFP Guidelines for the Management of Feline Hyperthyroidism. J Feline Med Surg 18(5): 400-416.

3. De Wet C S, Mooney CT, Thompson P N, Schoeman J P (2009) Prevalence of and risk factors for feline hyperthyroidism in Hong Kong. J Feline Med Surg 11(4): 315-321.

4. Pottenger L H, Domoradzki J Y, Markham D A, Hansen S C, Cagen S Z, et al. (2000) The relative bioavailability and metabolism of bisphenol A in rats is dependent upon the route of administration. Toxicol Sci 54(1): 3-18.

5. Norrgran J, Jones B, Lindquist N, Bergman A (2012) Decabromobiphenyl, polybrominated diphenyl ethers, and brominated phenolic compounds in serum of cats diagnosed with the endocrine disease feline hyperthyroidism. Arch Environ Contam Toxicol 63(1): 161-168.

6. Schug T T, Janesick A, Blumberg B, Heidel J J (2011) Endocrine disrupting chemicals and disease susceptibility. J Steroid Biochem Mol Biol 127(3-5): 204-215.

7. Souza HJM, Rezende PP, Corgozinho KB, Pereira AN, Cunha CSC, et al. (2007) Estudo preliminar do hipertiroidismo felino: Perfil clinico e laboratorial de 43 casos (1999-2006). Medvep - Revista Cientifica Veterinária de Pequenos Animais e Animais de Estimacao 4(15): 152157.

8. Wakeling J, Everard A, Brodbeld D, Elliot J, Syme H (2009) Risk factors for feline hyperthyroidism in the UK. J Small Anim Pract 50(8): 406414.

9. Koestel Z L, Backus R C, Tsuruta K, Spollen W G, Johnson S A, et al. (2017) Bisphenol A (BPA) in the serum of pet dogs following short-term consumption of canned dog food and potential health consequences of exposure to BPA. Sci Total Environ 579: 1804-1814.

10. Diamanti Kandarakis E, Bourguinon J P, Giudice L C, Hauser R Prins G S Soto A M, et al. (2009) Endocrine-Disrupting Chemicals: An Endocrine Society Scientific Statement. Endocr Rev 30(4): 293-342.

11. Edinboro CH, Thaker HL, Scott-Moncrieff JC, Glickman L (2004) Epidemiologic study of relationships between consumption of commercial canned food and risk of hyperthyroidism in cats. J Am Vet Med Assoc. 224(6): 879-886.

12. Karthikraj R, Borkar S, Lee S, Kannan K (2018) Parabens and their metabolites in pet food and urine from New York State, United States. Environ Sci Technol 52 (6): 3727-3737.

13. Serpe FP, Florito F, Esposito M, Ferrari A, Fracassi F, et al. (2018) Polychlorobiphenyl levels in the serum of cats from residential flats in Italy: role of indoor environment. J Environ Sci Health A Tox Hazard Subst Environ Eng 53(9): 1-9.

14. Peterson M (2012) Hyperthyroidism in Cats: What's causing this epidemic of thyroid disease and can we prevent it? J Feline Med Surg 14 (11): 804-818.

15. Junior AR, Haipek K, Oliveira RA, Daniel AGT, Taranti L (2007) Hipertireoidismo em felinos: Revisao de literatura e estudo retrospectivo. Medvep - Revista Cientifica Veterinaria de Pequenos Animais e Animais de Estimacao 5(14): 16-21.

16. Kass H P, Peterson M E, Levy J, James K, Becker D V, et al. (1999) Evaluation of environmental, nutritional, and host factors in cats with hyperthyroidism. J Vet Intern Med 13: 323-329.

17. Martin K M, Rossing M A, Ryland L M, DiGiacomo R F, Freitag W A (2000) Evaluation of dietary and environmental risk factors for hyperthyroidism in cats. J Am Vet Med Assoc 217(6): 853-856.

18. Kang JH, Kondo F (2002) Determination of bisphenol-A in canned pet foods. Research in Veterinary Science 73: 177-182.

19. Koeppe E S, Fergusson K K, Colacino J A, Meeker J D (2013) Relationship between urinary Triclosan and paraben concentrations and serum 
thyroid measures in NHANES 2007-2008. Sci Total Environ 445-446: 239-305.

20. Crossley V J, Debnath A, Chang Y M, Fowkes S R C, Elliot J, et al. (2017) Breed, coat color, and hair length as risk factors for hyperthyroidism in cats. J Vet Intern Med 31(4): 1028-1034.

21. Olczak J, Jones B R, Pfeiffer D U, Squires R A, Morris R S, et al. (2004) Multivariate analysis of risk factors for feline hyperthyroidism in New Zealand. New Zealand Veterinary Journal 53(1): 53-58.

22. Stephens M J, O Neill D G, Church D B, McGreevy P D, Thompson P C, et al. (2014) Feline hyperthyroidism reported in primary-care veterinary practices in England: prevalence, associated factors and spatial distribution. Vet Rec 175(18): 1-5.

23. Poppl A G, Carvalho G L C, Vivian I F, Corbellini L G, Gonzalez F H D (2017) Canine diabetes mellitus risk factors: A matched case-control study. Res Vet Sci 114: 469-479.

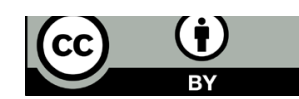

This work is licensed under Creative Commons Attribution 4.0 Licens DOI: 10.19080/JETR.2019.04.555650
24. Scott Moncrieff J C (2015) Feline Hyperthyroidism. In: Feldman E C, Nelson R W, Reusch C, Scott-Moncrieff J C, Behrend E (Eds). Canine and Feline Endocrinology, ( $4^{\text {th }}$ edn.) Saint Louis: Elsevier, pp. 136-195.

25. Chiu S L, Huskey W S (1998) Species differences in N-glucuronidation. Drug Metab Dispos 26(9): 838-847.

26. Mclean J L, Lobetti R G, Mooney C T, Thompson P M, Schoeman J P (2017) Prevalence of and risk factors for feline hyperthyroidism in South Africa. J Feline Med Surg 19 (10): 1103-1109.

27. Wooten K J, Smith P N (2013) Canine toys and training devices as sources of exposure to phthalates and bisphenol A. Chemosphere 93(10): 2245-2253.

Your next submission with Juniper Publishers
will reach you the below assets
- Quality Editorial service
- Swift Peer Review
- Reprints availability
- E-prints Service
- Manuscript Podcast for convenient understanding
- Global attainment for your research
- Manuscript accessibility in different formats
( Pdf, E-pub, Full Text, Audio)
- Unceasing customer service
Track the below URL for one-step submission
https://juniperpublishers.com/online-submission.php

